\title{
Squamous Cell Carcinoma of the Scalp Masquerading as Trichilemmal Tumor of the Scalp
}

\author{
${ }^{1}$ A Nanjundappa, ${ }^{2}$ Rajshekar Halkud, ${ }^{3}$ Bindu Venugopal, ${ }^{4}$ Purshottam Chavan, ${ }^{5} \mathrm{KT}$ Sidappa, ${ }^{6}$ Siddharth Biswas \\ ${ }^{7}$ M Samskruthi, ${ }^{8}$ Sudhir M Naik
}

\begin{abstract}
Background: Adnexal components tumors of the skin are very rare and are seen as benign lesions of the scalp in aged women. Trichilemmal tumor is usually benign and rarely undergoes malignant transformation in a stepwise manner starting with an adenomatous stage of the trichilemmal cyst to an epitheliomatous stage of the proliferating trichilemmal tumor (PTT) evolving into the carcinomatous stage of the malignant proliferating trichilemmal tumor (MPTT).

Case report: A 53-year-old woman reported with huge swelling in the posterior region of the scalp. The swelling was mobile and soft to firm in consistency not fixed to the skull bone. The surface was smooth and getting under the swelling was not possible, needle biopsy reported as trichilemmal tumor. Contrast enhanced computed tomography (CECT) neck did not show any nodes in the neck, especially the posterior compartment. The tumor was widely excised with $1 \mathrm{~cm}$ margin and the periosteum was kept intact with split skin graft. An area of periosteal adherence to the tumor seen was excised. The histopathology report on serial sectioning reported grade 1 moderately differentiated squamous cell carcinoma (SCC). Postoperative external beam radiotherapy of $66 \mathrm{~Gy}$ was given. The patient is being followed up and no recurrence is seen.
\end{abstract}

Conclusion: Malignant transformation in a proliferating trichilemmal tumor a rare entity and should be differentiated from SCC and the better prognostic trichilemmal carcinoma. A protocol-based adjuvant therapy is available for squamous cell carcinoma but not for trichilemmal carcinoma (TLC) and MPTT. A major meta-analysis may help to establish a clinical outcomebased classification and management protocol for these tumors.

Keywords: Trichilemmal tumor, Squamous cell carcinoma, Wide excision, External beam radiation.

How to cite this article: Nanjundappa A, Halkud R, Venugopal B, Chavan P, Sidappa KT, Biswas S, Samskruthi M, Naik SM. Squamous Cell Carcinoma of the Scalp Masquerading as Trichilemmal Tumor of the Scalp. Int J Head Neck Surg 2014;5(3):144-147.

Source of support: Nil

Conflict of interest: None

\footnotetext{
${ }^{1,6}$ Professor, ${ }^{2,4}$ Associate Professor, ${ }^{3}$ Senior Resident

${ }^{5}$ Assistant Professor, ${ }^{7,8}$ Fellow

1,2,4,5,7,8 Department of Head and Neck Oncosurgery, Kidwai Memorial Institute of Oncology, Bengaluru, Karnataka, India

${ }^{3}$ Department of Radiation Oncology, Kidwai Memorial Institute of Oncology, Bengaluru, Karnataka, India

${ }^{6}$ Department of Pathology, Kidwai Memorial Institute of Oncology, Bengaluru, Karnataka, India
}

Corresponding Author: Sudhir M Naik, Fellow, Department of Head and Neck Oncosurgery, Kidwai Memorial Institute of Oncology, Bengaluru, Karnataka, India, Phone: 09916807109 e-mail: sud223@gmail.com

\section{INTRODUCTION}

Malignant proliferating trichilemmal tumor (MPTT) is a rare neoplasm arising from the external root sheath of the hair follicle seen in women over the 6th decade. ${ }^{1-3}$ They vary from well circumscribed to irregularly defined subcutaneous nodules with squamoid cytologic features and trichilemmal-type of keratinization with cystic to firm in consistency. ${ }^{2,4}$ This initially described with confusing histologic features of squamous cell carcinoma (SCC). ${ }^{5}$ The tumor is also called epidermoid cyst, pilar tumor of the scalp, proliferating trichilemmal cyst, proliferating epidermoid cyst, giant hair matrix tumor, hydatidiform keratinous cyst, trichochlamydo carcinoma, and invasive hair matrix tumor. ${ }^{6}$

Incidences are seen in older age females predominantly affecting the scalp and rarely eyelids, neck and face., While MPTT usually arises as a subepidermal tumor, the other similar tumor trichilemmal carcinoma (TLC) occurs as exophytic, popular or nodular lesion measuring less than $2 \mathrm{~cm} .{ }^{3}$ This malignant lesion is seen in the sunexposed scalp, solar keratosis, scars of burns, following high-dose radiation exposure and in post-transplant states. ${ }^{5}$ The incidence of benign is more compared to the malignant appendageal tumors, only few reports in literature with an aggressive clinical course and a propensity for nodal and distant metastases. ${ }^{9}$ Malignant proliferating trichilemmal tumor (MPTT) is a very uncommon tumor may be seen as longstanding nodular scalp lesions and histological evidence of significant abnormal mitosis, marked cellular pleomorphism, infiltrating margins and aneuploidy reflect malignant transformation. ${ }^{10}$

We report a case of SCC masquerading as MPTT of the scalp. Initially, it appeared as a benign trichilemmal tumor, later on serial sectioning of the suspicious margins moderately differentiated SCC was confirmed.

\section{CASE REPORT}

A 53-year-old woman reported with huge swelling in the posterior region of the scalp. It was a soft-tissue swelling $12 \times 12 \times 12 \mathrm{~cm}$ in dimensions. The swelling was mobile and soft to firm in consistency not fixed to the skull bone (Fig. 1). The surface was smooth and getting under the swelling was not possible. Routine investigations, fine 
needle aspiration cytology (FNAC), contrast enhanced computed tomography (CECT) brain with enhanced bone window, magnetic resonance imaging (MRI) was done.

Trichilemmal tumor of skin appendages was reported. CECT neck did not show any nodes in the neck, especially the posterior compartment. The tumor was widely excised with $1 \mathrm{~cm}$ margin and the periosteum was kept intact. Split skin graft was harvested from the medial side of the thigh and the defect covered with it under general anesthesia (Fig. 2). An area of periosteal adherence to the tumor was excised. The histopathology report on serial sectioning reported grade 1 moderately differentiated SCC. Patient was planned with postoperative radiotherapy of $66 \mathrm{~Gy}$ in 33 fractions with electrons of $6 \mathrm{MeV}$ to a depth of $2 \mathrm{~cm}$ prescribed to $90 \%$ isodose. The treatment area was defined as the volume of tumor with microscopic

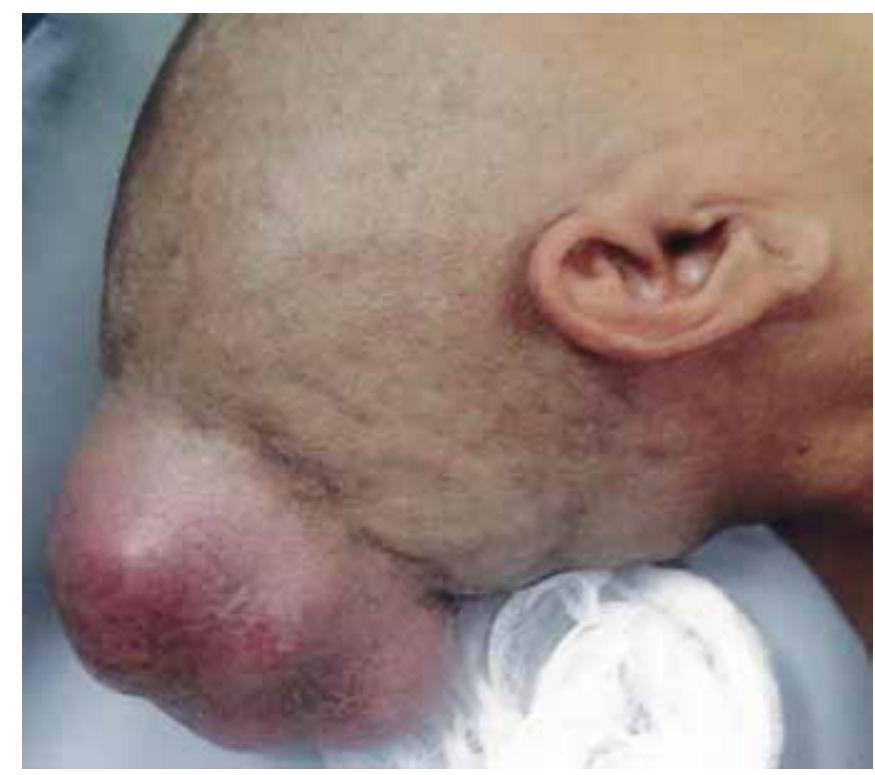

Fig. 1: Huge swelling in the posterior region of the scalp

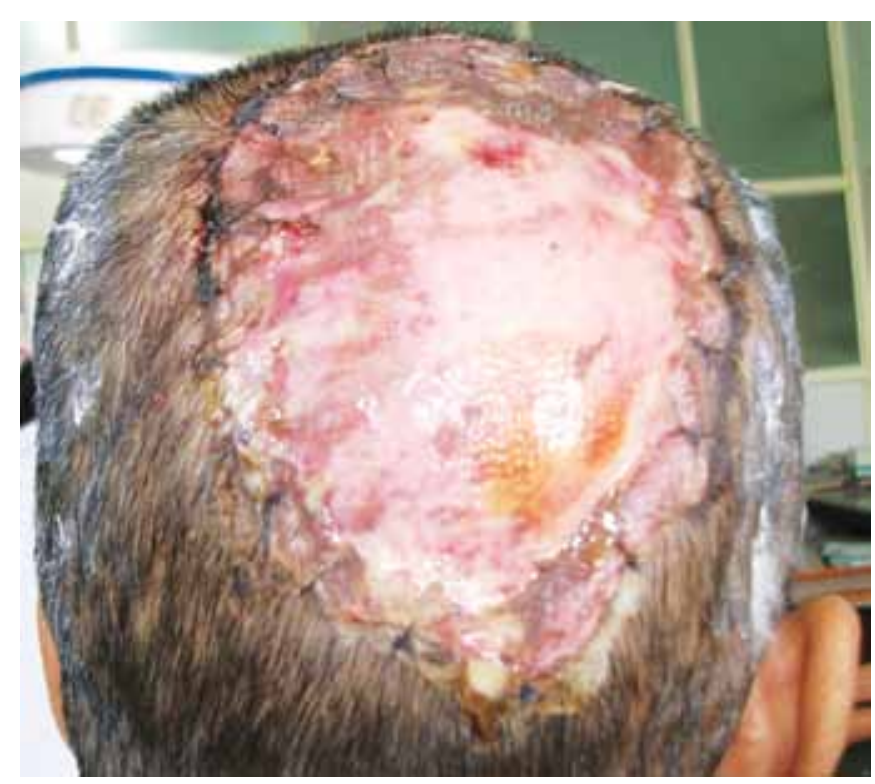

Fig. 2: Postoperative 1 week after the excision and skin grafting extension with a $1 \mathrm{~cm}$ margin. Customized cerrobend electron cut-outs were made, and the patient was treated in prone position to avoid scatter dose to critical structures and achieve uniform dose distribution. The patient was examined at the beginning of treatment and weekly thereafter till the end of treatment. She experienced grade II skin reaction at the end of therapy. The patient is being followed up and no recurrence is seen.

\section{DISCUSSION}

Tumors arising from the adnexal components of the skin pilosebaceous unit, eccrine or apocrine glands are very rare and display more than one line of differentiation. ${ }^{11}$ Most of the tumors are benign, but malignant varieties also exist which are very rare, locally aggressive, having potential for nodal and distant metastasis, with a poor prognosis. ${ }^{11}$ So, hunting for features of malignancy in these mostly benign tumors seems challenging as the incidences are very low. ${ }^{11}$

Adnexal components tumors of the skin are very rare and are seen as benign lesions of the scalp in aged women. ${ }^{12,13}$ The benign includes trichofolliculoma, desmoplastic trichoepithelioma, trichoblastoma, trichoblastic fibroma, trichoadenoma, proliferating trichilemmal tumor, trichilemmoma, desmoplastic trichilemmoma, pilomatricoma, sebaceous adenoma and sebaceous epithelioma. ${ }^{12,13}$ The malignant includes TLC, trichoblastic carcinoma, MPTT, pilomatrix carcinoma, sebaceous carcinoma, basal cell carcinoma with sebaceous differentiation. ${ }^{11}$

They are not seen in the alopecic individuals, as lanugo hair follicles of the bald scalp and follicles of other areas devoid of non-terminal hair are unlikely to produce these tumors. ${ }^{9}$ They are seen in areas of excess hair growth arising through increased epithelial proliferation within pilar or sebaceous cysts. ${ }^{9}$ The tumor may be of a long standing cyst like lesion on the scalp which has to be differentiated from well-differentiated carcinoma. ${ }^{14}$ Trichilemmal tumor is usually benign and rarely may undergo malignant transformation in a stepwise manner starting with an adenomatous stage of the trichilemmal cyst to an epitheliomatous stage of the PTT evolving into the carcinomatous stage of the MPTT. ${ }^{5}$

Malignant and benign tumors can be differentiated on the basis of morphological criteria, i.e. rate of growth, invasion and metastasis and functional criteria, i.e. anaplasia and cellular atypia. ${ }^{15}$ Clear cells appearing from the outer root sheath of hair exhibiting marked pleomorphism and atypical mitosis, with nodular trabecular formation of keratinocytes with a sharp border between parenchyma and stroma confirms thetrichilemmal tumor. ${ }^{13}$ The rare malignant change has a circumscribed 
nodular or a diffuse spindle cell type which has to differentiated from metastases of spindle cell tumors with regions of squamous differentiation. ${ }^{1}$ MPTT has trichilemmal keratinization, lobular pattern and the lack of a precursor epidermal lesion such an actinic keratosis while SCC has fields of keratin production. ${ }^{16}$ MPTT metastasize and recurs more frequently than SCC and resembles TLC on histology. ${ }^{16} \mathrm{~A}$ trichilemmal tumor has to be differentiated from sebaceous carcinoma, clear cell hidradenocarcinoma, cutaneous metastasis of renal cell carcinomas, MPTT, TLC and SCC. ${ }^{6,14}$ Trichilemmal carcinoma usually shows continuity with the epidermis or follicular epithelium as a pagetoid interface and exhibits trichilemmal keratinization and dermal invasion. ${ }^{17}$

Ye et al categorized these tumors on histopathological characteristics and invasiveness. ${ }^{4}$ Group I had no infiltration of surrounding stroma and minimal nuclear atypia; they showed trichilemmal keratinization, stromal invasion with a mononuclear infiltrate of plasma cells and lymphocytes, and dystrophic calcification and were considered as benign tumors. ${ }^{4}$ Group II was early invasive, with modest cytological abnormalities, eosinophilic cytoplasm and loose edematous stroma with minimal to moderate infiltration by mononuclear inflammatory cells; they were considered locally aggressive. ${ }^{4}$ Group III tumors were invasive; they were cytologically anaplastic and were, therefore, considered malignant. Statistically, significant difference in terms of local control and lymph node metastatic potential was found between the groups. ${ }^{4}$

Malignant proliferating trichilemmal tumor on gross pathology shows solid, lobular and trabecular areas with periodic acid schiff (PAS) stain-positive hyaline membrane. ${ }^{18}$ Large oval to polygonal tumor cells with moderate cytological atypia with focal areas of pilar type of keratinization with peripheral palisading of cells. ${ }^{9}$ Infiltration into the dermis, features of necrosis, calcification with individual cell keratinisation and mitotic figures are seen. ${ }^{9}$ As the malignant changes are very rare in trichilemmal tumor, metastasis are hardly documented and may be seen as sudden rapid growth. ${ }^{15,19}$ The classification is a histopathological and not clinical and so a composite classification based on both features are essential for accurate management. ${ }^{15,19}$ All MPTT expresses immunostaining to cytokeratin 5 and 6 , while the normal immunoreactivity pattern for CD 34 noticed in tumors of outer root sheath is lost due to undifferentiation..$^{20,21}$ A heterogenous enhanced mass with poorly-defined margins is seen on MRI. ${ }^{18}$

A meta-analysis on aggressive variant, the MPTT was done which confirmed it to be aggressive and has tendency to recur and metastasize distantly. ${ }^{22}$ Here, adjuvant therapy was not used and the outcome was variable, which led for a possible role of adjuvant radiotherapy or chemotherapy to improve disease-free survival. ${ }^{6}$ Ye et al reported 50\% recurrence in MPTT within 2 to 14 months where none had been given adjuvant therapy. ${ }^{4}$ Trichilemmal carcinoma (TLC) is treated with wide local excision as the lesion is slow growing with no reported incidences of recurrence or metastasis. ${ }^{23}$ MPTT needs a wide local excision with a $1 \mathrm{~cm}$ margin of normal tissue with regular follow-up. ${ }^{23}$ Role of adjuvant radiation and chemotherapy in MPTT is suggested as the tumor has high rates of locoregional recurrence and distant failures due to its aggressive nature. ${ }^{1}$ As the incidences are low, the added advantage of adjuvant therapy is not established. ${ }^{1}$ However, in view of the malignant squamous cell component of the tumor, we considered it prudent to irradiate the patient..$^{24}$ The various modalities of radiotherapy practised for skin tumors include superficial X-ray, electrons, photons, brachytherapy or a combination of any of the above. ${ }^{25}$ Since electrons have been established as equivalent to superficial X-ray, we chose electron beam therapy as it was easily available at our institute. ${ }^{26,27}$

Unlike head and neck SCC which are locoregional, pilar tumors are primarily local only and managed with wide local excision. ${ }^{1}$ The tumor may present as a large fungated mass and the presence of multiple histopathologically-proven metastatic nodes with perinodal extension and may need wide excision and adjuvant therapy. ${ }^{1}$ An accurate analysis of the histopathology is necessary as MPTT is a rare variant and more studies are required to place adjuvant therapy as a protocol for these tumors. ${ }^{1}$ Mann et al reported metastasis from trichilemmal tumors, while Seff and Berkowitz reported cer-vical metastasis from MPTT and dissemination. ${ }^{28}$

\section{CONCLUSION}

Malignant transformation in a proliferating trichilemmal tumor a rare entity and should be differentiated from squamous cell carcinoma and the better prognostic trichilemmal carcinoma. A protocol-based adjuvant therapy is available for SCC but not for TLC and MPTT. A major meta-analysis may help to establish a clinical outcome-based classification and management protocol for these tumors.

\section{REFERENCES}

1. Siddha M, Budrukkar A, Shet T, Deshpande M, Basu A, Patil N, et al. Malignant pilar tumor of the scalp: a case report and review of literature. J Cancer Res Ther Dec 2007;3(4): 240-243.

2. Wick MR, Swanson PE. Cutaneous adnexal tumors: a guide to pathologic diagnosis. Chicago, IL: ASCP Press; 1991. p. 2; 113-168.

3. Satyaprakash AK, Sheehan DJ, Sangüeza OP. Proliferating trichilemmal tumors: a review of the literature. Dermatol Surg 2007 Sep;33(9):1102-1108. 
4. Ye J, Nappi O, Swanson PE, Patterson JW, Wick MR. Proliferating pilar tumors: a clinicopathologic study of 76 cases with a proposal for definition of benign and malignant variants. Am J Clin Pathol 2004;122(3):566-574.

5. Rao S, Ramakrishnan R, Kamakshi D, Chakravarthi S, Sundaram S, Prathiba D. Malignant proliferating trichilemmal tumour presenting early in life: an uncommon feature. J Cutan Aesthet Surg 2011;4(1):51-55.

6. Brownstein MH, Arluk DJ. Proliferating trichilemmal cyst: a simulant of squamous cell carcinoma. Cancer 1981;48(2):12071214.

7. Trabelsi A, Stita W, Gharbi O, Kanani N, Sriha B, Korbi S. Malignant proliferating trichilemmal tumor of the scalp: a case report. Dermatol Online J 2008;14(3):11.

8. Garg PK, Dangi A, Khurana N, Hadke NS. Malignant proliferating trichilemmal cyst: a case report with review of literature. Malays J Pathol 2009;31(2):71-76.

9. Saida T, Oohara K, Hori Y, Tsuhiya S. Development of a malignant proliferating trichilemmal cysts. Dermatologica 1983;166(2):203-208.

10. Alsaad KO, Obaidat NA, Ghazarian D. Skin adnexal neoplasms-part 1: an approach to tumours of the pilosebaceous unit. Clin Pathol 2007;60(2):129-144.

11. Brenn T, McKee PH. Tumours of the hair follicle. In: McKee $\mathrm{PH}$, Calonje E, Granter SR, editors. Pathology of the skin with clinical correlations. 3rd ed. Amsterdam: Elsevier; 2005. p. 1519-1563.

12. Rodriguez-Diaz E, Armio M. Mixed tumors with follicular differentiation: complex neoplasms of the primary epithelial germ. Int J Dermatol 1995;34(5):782-785.

13. Klein W, Chan E, Seykora JT. Tumors of the epidermal appendages. Elder DE. Lever's histopathology of the skin. 9th ed. Philadelphia, PA: Lippincott Williams and Wilikins; 2005. p. 867-926.

14. Shet $\mathrm{T}$, Modi C. Nucleolar organizer regions (NORs) in simple and proliferating trichilemmal cysts (pilar cysts and pilar tumors). Ind J Pathol Microbiol 2004;47(1):469-473.

15. Stricker TP, Kumar V. Neoplasia. In: Kumar V, Abbas AK, Fausto N, Aster J, editors. Robbins and Cotran Pathologic Basis of Disease. 8th ed. New Delhi: Elsevier; 2010. p. 173-223.
16. Yotsuyanagi $T$, Urushidate S, Yokoi K, Sawada Y. A malignant proliferating trichilemmal tumor simulating a squamous cell carcinoma. Eur J Plast Surg 1997;20(3):320-322.

17. Swanson PE, Marrogi AJ, Williams DJ, Cherwitz DL, Wick MR. Trichilemmal carcinoma: clinicopathologic study of 10 cases. J Cutan Pathol 1992;19(1):100-109.

18. Kim HJ, Kim TS, Lee KH, Kim YM, Suh CH. Proliferating trichilemmal tumors: CT and MR imaging findings in two cases, one with malignant transformation. AJNR 2001;22(2): 180-183.

19. Folpe AL, Reisenauer AK, Mentzel T, Rütten A, Solomon AR. Proliferating trichilemmal tumors: clinicopathologic evaluation is a guide to biologic behavior. J Cutan Pathol 2003;30(2): 492-498.

20. Plumb SJ, Argenyi ZB, Stone MS, De Young BR. Metastatic adenocarcinoma. Am J Dermatopathol 2004;26(4):447-451.

21. Herrero J, Monteagudo C, Ruiz A, Llombart-Bosch A. Malignant proliferating trichilemmal tumors: an histopathologic and immunohistochemical study of three cases with DNA ploidy and morphometric evaluation. Histopathology 1998;33(3):542-546.

22. Poiares Baptista A, Garcia E Silva L, Born MC. Proliferating trichilemmal cyst. J Cutan Pathol 1983;10(2):178-187.

23. Reis JP, Tellechea O, Cunha MF, Baptista AP. Trichilemmal carcinoma: review of 8 cases. J Cutan Pathol 1993;20(2):44-49.

24. Takayasu S, Yoshiyama M, Kurata S, Terashi H. Lymphoepithelioma-like carcinoma of the skin. J Dermatol 1996;23(7): 472-475.

25. Locke J, Karimpour S, Young G, Lockett MA, Perez CA. Radiotherapy for epithelial skin cancer. Int J Radiat Oncol Biol Phys 2001;51(3):748-755.

26. Griep C, Davelaar J, Scholten AN, Chin A, Leer JW. Electron beam therapy is not inferior to superficial X-ray therapy in skin carcinoma. Int J Radiat Oncol Biol Phys 1995;32(5): 1347-1350.

27. Kwan W, Wilson D, Moravan V. Radiotherapy for locally advanced basal cell and squamous cell carcinomas of the skin. Int J Radiat Oncol Biol Phys 2004;60(2):406-411.

28. Mann B, Salm R, Azzopardi JG. Pilar tumor. A distinctive type of trichilemmoma. Diagn Histopathol 1982;5:157-167. 